Scriptura S 2 (1986), 1-20.

\title{
PHILOSOPHY: MAN'S MIRROR
}

\author{
Prof G A Rauche \\ Faculty of Theology \\ University of Durban-Westville \\ Durban
}

\section{ABSTRACT}

Philosophical "projects", no matter by what method they are conceived and from what historical situation they are postulated, are man's mirror. This means that they reflect the prevailing historical conditions of the age: the specific conflicts of the time and the specific needs arising from these conflicts. It also means that they are postulated to cope with these conflicts and needs in methodological form, in this way ordering man's surroundings in a rational manner, thus serving as guides under specific historical circumstances. It means further that they enter into a controversial and critical relationship with one another, which represents philosophical thought as a continuing dynamics of critical argument. The critical relationship between historical philosophical projects point to the real ground from which these projects are developed: man's contingent experience of the world. It is on the grounds of his changing experience of the world that the philosophical argument continues about the basic questions of "knowledge;. being, justice, freedom, harmony and truth. It is in the light of the continuing philosophical argument that a philosophia perennis exists. 


\section{THE PROBLEM OF DEFINTTION}

When a man asks a philosopher: . What is philosophy? the philosopher might not come out with a straightforward definition, but might, instead, plunge into a lenghty explanation, of which the man posing the question understands very little and which keeps him puzzled. Indeed, there is no ready-made answer to this question. The moment it is posed, we are already philosophizing. The latter is an intellectual activity, which involves man's whole self and his whole being.

The various philosophical theories which are constituted and reconstituted throughout history are, at the same time, human self-projections into the world. They represent so many cycles of the self, of man's self-realization into the world. They form changing truth-perspectives of the world, man's position in the world and man's relationships with his fellow-man (society and the state). As such, they reflect the conflicts with which man wrestles in a specific historical situation as well as the need of overcoming them: the concrete socio-political needs arising from these conflicts. Seen in the context of the critical relationship into which they enter with one another, these truth-perspectives reflect man's changing experience of the world or reality: his contingent experience of it. Forming cycles of the self, philosophical theories are truth-perspectives through which man orders and reorders his contingent experience of the world (reality) in a methodological manner. Their subjective character is thus obvious. In trying to get the prevailing conflicts of their time under control, in this way coping with the socio-political needs arising from them, they serve man as a rational guide which, under the given circumstances, renders his existence meaningful. From the existential point of view, philosophical theories represent intellectual projects of man's continual self-realization under changing circumstances of life or changing historical conditions.

The above shows that the answers philosophy provides in certain situations cannot be conclusive but are controversial. They raise fresh problems, so helping to change socio-political conditions in their own turn. This results in an interplay of theory and practice. Philosophical theories rise from practice, from man's need to overcome the conflicts experienced at a certain time. On the other hand, philosophical theories point beyond the conditions of their time, so effecting a change of 
practice. Philosophy is man's mirror in the sense that it reflects his essentially problematic and controversial being. Its contingent projects of human self-realization point to man's finite, historical and contingent nature. To demand of philosophy that it should provide conclusive answers, is to ignore man's true nature. If man is fallible, limited, problematic and controversial, philosophy cannot be otherwise, for it is man who philosophizes. If man knew the Truth, he would stop philosophizing. Since he does not know and will never know, philosophy will continue. As long as there is man, so long will there be philosophy.

The question: Why philosphy? is tantamount to the question: Why man? It is a futile question. Because there is man with all his shortcomings and limitations, there is philosophy with all its deficiencies. The two are inseparable. Philosophy flows from man's contingent experience of life and his essentially problematic and contradictory nature. Philosophical theories must be seen as man's crutches on which he limps through life and through history. They afford him world orientation under particular historical conditions, in a particular existential situation.

The fact that are no conclusive answers provided by philosophy, that there is no definition assented to by all philosophers, that the many philosophical theories conceived throughout history may be said to contain definitions of their own, has been termed the Scandal of Philosophy: its failure to achieve knowledge, the evidence of which is acknowledged by all philosophers. No less a thinker than Karl Jaspers has pointed out that such criticism shows a misconception of philosophy's true character, that it overlooks the existential involvement of the philosopher, his personal engagement in the philosophical enterprise, his being inextricably involved in the historical conditions and the intellectual climate of his own time. It has already been pointed out that philosophical theories are, at the same time, projects of man's selfrealization in the world.

From the point of view of systematic philosophy, it can be established that philosophy keeps asking certain basic philosophical questions, which have been clearly formulated by Plato. This enabled Alfred North Whitehead to say that Western philosophy is a series of footnotes to Plato. These basic questions are the questions about knowledge, being, 
justice, harmony (beauty) and truth (meaning). These questions, which Plato conceived as aspects of agathon (goodness), yield the corresponding philosophical disciplines: epistemology, metaphysics, ethics, aesthetics and logic.

Philosophy's chief dilemma is that it asks these basic questions in general, or universal, way, while the answers it gives to them remain problematic and controversial. It is, however, this fact which makes possible the continuation of philosophical argument. If answers could be arrived at which were acknowledged by all, if conclusive answers could be given to philosophy's basic questions, then man would stop philosophizing. In this case, however, he would no longer be man. In knowing the Truth he would be like God, at least as the latter is commonly conceived: as an infinite, immutable, omnipotent and omniscient being. In short, God is seen as perfect, in contrast to man who is certainly imperfect. It is, however, precisely when we take man as man, with all his aspirations, needs, shortcomings, weaknesses, failures and limitations that we begin to understand the meaning of philosophy as well as the need for continued philosophical argument. It is as a historical process of thinking that philosophy becomes man's mirror. Looking at these various philosophical projects in historical context, man begins to understand himself as a thinking and acting being. He recognizes the interplay between theory and practice. The history of philosophy affords him self-understanding as a finite, historical and contingent being, who in his striving for freedom and authentic existence is referred to his fellow-man as his indispensable partner.

As shall be shown in greater detail later on, critical and self-critical dialogue between man and his fellow-man concerning the basic philosophical questions under changing historical conditions is the prerequisite for leading an authentic life in freedom, a life in conformity with reality. It would be then that man is at peace with the world, with himself and his fellow-man: that he is happy. Such authentic existence can be based only on man's and his fellow-man's restriction to the field of their basic common experience: the contingent experience of the world (reality). Contingent experience is the realm of freedom in the sense that, from it, man and his fellow-man posit their respective truthperspectives in the world and, in so doing, enter into critical argument with each other in an open, tolerant and constructive spirit, in this way co-operating in the common 
task of building a better world and a better society. The dynamics of philosophical argument generated by man's contingent experience of the world (reality) basic to all men, constitutes the true philosophia perennis.

In the light of the above, it becomes clear that definitions of philosophy such as: the pursuit of knowledge (Pythagoras), the search of truth (Socrates), the of fspring of wonder (Plato but also Kant) are subjective. That is so because such definitions are made on the grounds of the respective philosopher's Weltanschauung, from which his philosophical theory derives. A further difficulty of giving an objective definition of philosophy is that it asks the question about truth in an absolute manner but provides only relative answers. The latter are meaningful only within the methodological framework of a theory as a system of reference, and so remain controversial, standing in contradiction to the answers given by other theories. Hegel's statement: "Philosophy defines all else but cannot itself be defined", sums up the situation, although he was referring to his own philosophy.

Aforegoing remarks should have shown that the nature of philosophy can best be established by studying its history. The critical relationship into which philosophical theories enter with one another and ensuing philosophical argument, the dynamics of which is generated by man's contingent experience of reality, reveal philosophy not as one closed system, which provides all the answers, but as an open critical discipline. Philosophical theories constitute man's changing experience of life in methodological form. They articulate man's needs and aspirations as they arise from the socio-political conflicts of the given historical situation, e.g. the socio-political conflicts in the oligarchic polis: between aristocrats and democrats, rich and poor, which Plato's philosophy attempted to overcome by designing the ideal state in the Republic (Cornford, 1941); the socio-political conflicts that ensued as a result of the French Revolution and with which both Kant's and Hegel's philosophies sought to cope; the socio-political confliets yielded by the Industrial Revolution in the 19th century: the class-struggle which in Marx's philosophy becomes instrumental in achieving the just, free and classless society. Thus the whole truth about philosophy is that it could be designated as the science of changing human world experience, which causes man to enter into critical argument (dialogue) with his fellow-man, 
concerning the great themes of knowledge, being, justice, freedom and truth (goodness). The dynamics of philosophical argument shows man both his limitations and his possibilities: especially the possibility for freedom. Articulating man's changing world consciousness, philosophy could be defined as: the science of actuality.

This definition covers the fact that philosophy is the outcome of the natural conflict that inevitably obtains between man and his fellow-man. Natural conflict which must be ascribed to man's finiteness, history and contingency, in short to man's limitation and controversiality, must not be confused with confrontation. While the former, if accepted by man and his fellow-man as inevitable, might lead to a real encounter and genuine communication, while it really forms a bridge rather than a wall, the latter is total and destructive. It is the result of the absolutization of one, philosophical truthperspective, which is lifted out of the historical dynamics of argument and declared the Truth, thus total. This results in the deterioration of a philosophical theory, or truthperspective, which is converted into a totalitarian ideology. The latter is repressive and suffers no criticism of its underlying premises. It changes the open dynamies of philosophical argument into one closed system, alienating man from his fellow-man and turning man's open critical dialogue with him into repressive monologue. A case in point is the monologue of totalitarian functionalism of the West's monopolistic technological society, which is on the point of becoming a technocracy, on the one hand, and, on the other, the totalitarian ideologism of the state-monopolistic society in the East. Both of these systems are in the deadly grip of destructive confrontation, which may lead to mankind's extinction. Such destructive confrontation leads to what the ancient Greeks called hubris. While natural conflict is a bridge between man and his fellow-man, which facilitates rational argument in the spirit of selfrestraint, modesty, tolerance, open-mindedness, respect and goodwill, total confrontation converts these virtues into greed, arrogance, self-righteousness, $\operatorname{dog} m a t i s m$, contempt and a limitless willto-power. By and large, the repressive monologue of totalitarian systems, their one-dimensional functionalism and ideologis $\mathrm{m}$, results in a monotony which breeds in man unease, despair and violence, as they are experienced today.

It follows that man is free and leads an authentic existence only when philosophical theories - and theories for that 
matter - are seen in historical context, as links in a dynamics of critical argument, out of which no theory can be lifted laying claim to representing universal truth. Such a procedure would mean the fossilization of one particular truth-perspective. It would result in freezing man's contingent experience of reality in such a way that he would be estranged from himself and his fellow-man. The price to be paid would be endless suffering through repression and oppression. Only if philosophy remains open to the changing circumstances of life, only if the problematic and controversial nature of its theories are accepted in the awareness of man's limitations, the experience of which refers him to his fellow-man in the permanent struggle for authentic existence, can man remain free and an open society be built. The definition, therefore: philosophy is the seience of actuality - the methodological constitution and reconstruction of man's contingent (variable) experience of the world (reality) - is of enormous practical consequence. It points the way to man's freedom.

THE MAN-MADENESS OP THE PHILOSOPHICAL TRUTH-PERSPECTIVE

In terms of this volume's title: Text and Context, it is the purpose of this essay to show that philosophical text must always be read in methodological context. This statement means that the meaning of a specific philosophical theory's concepts must be derived from the method by which the theory is constituted under specific historical conditions. It means further that, ultimately, philosophical theories must be seen in historical context: in terms of the critical relationship into which they enter with one another and which shows philosophy as the dynamics of philosophical argument carried on between man and his fellow-man under historical conditions.

As far as the man-madeness of philosophical truthperspectives is concerned, this has already crystallized in the section dealing with the problem of definition. The manmadeness of philosophical knowledge - as any other scientific kind of knowledge, for that matter - can be strikingly shown in terms of the various methods by which it is constituted. In its continued search for the knowledge of the truth, philosophy resorts to experience and reason. It may be said 
that it applies rational judgement to man's contingent experience of reality. It achieves knowledge by methodologically constituting this experience in the form of a theory. On the grounds of its rationality and intelligibility, the latter represents a truth-perspective, which has been conceived under the prevailing historical conditions of the time. It both reflects and points beyond these conditions. The constitution of man's contingent experience by a certain method makes it possible to speak about philosophy as a science. Taken as a wider concept, science means the methodological constitution of the various types of human experience: physical, historical, aesthetic, philosophical, religious, etc. which yields various types of knowledge. No scientific knowledge is possible without method.

In natural science Newton's theory of gravitation would be a good example. It is constituted by "facts" (observations and experimentations) through the inductive method. In the modern science of physics the functional relations between atomic events - which relations can also said to be manmade in the sense that they are established under man-made experimental conditions and with the aid of man-made experimental apparatus ( $M$ Born, 1965:105-107) - are established by mathematical equations. In this way is it hoped to standardize these relations and so to establish a new form of static causality, the mechanical causality of Newton's physics having been underminded and replaced by Heisenberg's uncertainty principle, which governs contemporary atomic physics.

In contradistinction to the individual sciences - physics or history, for example, which constitute man's experience in a clearly circumscribed field: the experience of physical objects and the experience of human action in past and present, respectively - philosophy deals with the whole scale of human experience. Apart from the experience of natural phenomena, which is dealt with by epistemology, it articulates metaphysical, moral and aesthetical experience in methodological form. From this it can be seen that there is not only one type of knowledge, but that there are many types constituted methodologically from a certain type of human experience. Since all types of scientific knowledge require method, logic may be considered the common link, since method is based on logical reasoning: deductive, inductive, transcendental, analytical, dialectical, etc. It is when the act of reasoning is performed in a pure form when 
it is not applied to experience, that the discipline of logic is constituted. Like the theories of other philosophical disciplines, theories of logic, too, remain problematic and controversial, thus giving rise to various forms of logic, as can be seen from its development from Aristotle's two-valued subject-predicate logic into modern many-valued propositional logic under changing historical conditions. In the Middle Ages it was Aristotelian syllogistic logic which can be regarded as the world formula for the Christian cosmos of mediaeval man and society. It was the vehicle of theology, which was then the queen of the sciences.

With the advent of modern science under changed conditions of life, which bred a different intellectual climate and a completely different concept of knowledge, formal reasoning required more than syllogistic logic. The logical argument began to gather momentum in the 17th century when syllogistic logic was called into question by the influential Logique de Port Royal, advocated by Arnauld and Nicole. Roughly speaking, it may be said that, while the traditional syllogistic of the Middle Ages complied with man's theocentric outlook at that time being instrumental in deriving the rational structure of the cosmos from God, contemporary propositional logic complied with contemporary man's interest in fuctional processes and eyents. This interest is reflected in Einstein's equation $E=\mathrm{m}^{2}$, which represents the new world formula. The changing concept of knowledge indicates another difference between philosophy and the individual sciences. While physies and history, for instance, describe the "facts" of their respective field of enquiry, which "facts" they take for granted while philosophy asks the question: What are facts? philosophy deals with the changing concept of knowledge as such. Rather than describing facts, it asks questions about the origin, nature and extent of knowledge.

Since human experience is manifold, any kind of onedimensional thinking as it is experienced in contemporary technological society, where one type of experience, thus one type of knowledge, namely, functional or operational knowledge, has been absolutized, is directed against authentic human nature. Marcuse (1968) and Ernest Gellner (1968) have shown that such one-dimensional thinking as it finds expression in neo-positivistic thought - logical positivism and linguistic philosophy (Wittgenstein, Carnap, Ryle, Austin) - is not only barren and foreign to life, but that it is also the 
way of thinking of a repressive society (Marcuse). Man's variegated experience and his contingent experience of reality refuse to be crammed into the straitjacket of one particular method like the analytical one of neo-positivistic philosophy: the negation of any reflective or transcendental form of philosophy. Contemporary analytical philosophy permits critical argument only within the precinets of its methodology, not outside it. For this reason it is really uncritical and dogmatic. By a great deal of knuckle rapping and whistle blowing it seeks to quell man's natural tendency: the asking of philosophical, or metaphysical, questions, without which the dynamics of philosophical argument would stop. The reduction of reflective individual consciousness to functional language relations resembles a successful operation during which the patient died.

This does not mean that analytical philosophy has no rightful place within the context of philosophical argument. It has grown under the impact of modern scientific thinking, the changed historical conditions and the changed intellectual climate that gave rise to the modern atomistic, or piecemeal, way of thinking: a thinking in terms of events and their functional relations. In the wake of economic, social and political changes, the traditional constitutive approaeh of metaphysics and transcendental philosophy appeared redundant. In order to be relevant, philosophy had to adopt scientific (analytical) methods (H. Reichenbach, 1958).

As a method that had grown under specific historical circumstances, analytical philosophy had a definite rôle to play within the dynamics of philosophical argument. As a specific approach among other approaches to the problem of dealing with the new situation, it could not expect to go unchallenged ( $H$ D Lewis, 1963). It obviously failed to achieve its aim of arriving at a neutral meta-language. This third vision approach was never realized, and always turned out to be a first vision approach (E Gellner, 1968:86-96). This proved that the subjective factor cannot be overcome by any method, transcendental or analytical. In fact method represents the subjective factor, as also emerges from its meaning: the way or approach. It renders any theory transcendental. A method of whatever type is always manmade and modifiable. . 
While thus analytical philosophy's rightful place and position function within the context of philosophical argument are fully acknowledged, the claim by many of its representatives that it is the only valid and relevant approach today, that its propositions alone are meaningful, is rejected. These assertions hold true only within the frameword or reference of the analytical method, not outside it, since the premises of its theories are questionable. No scientific, or philosophical, method can cover all aspects of life. Language has not only one functional dimension but has a variety of dimensions, as, among others, $N$ Chomsky has shown (1966). Ultimately, man is a multi-faceted being, whose manifold forms of experience cannot be captured by one particular method or theory. It is not method, or theory, which determines reality, but it is man's contingent experience of reality from which method and theory flow. Linguistics stands refuted by life's contingency. Like any other theories it is subjective, because it is based on man-made method. As such it is itself transcendental.

It emerges that any philosophical truth-perspective is manmade and being the outcome of the methodological constitution of human experience is really transcendental in so far as such constitution yields theory. Method may be described as the truth-function of knowledge. It is method which constitutes scientific knowledge as intelligible theory which forms a certain truth-perspective. In the light of changing historical conditions, such theory remains controversial amd invites the postulation of new theories under changed circumstances of life.

If science were defined as methodologically constituted types of knowledge under man's changing experience of reality, yielding various theories which enter into a critical relationship with each other, thus generating the dynamies of scientific argument, it would be evident that knowledge of the truth is perspectival. Knowledge is not something that is received from so-called facts. From the philosophical point of view the latter are controversial and, in reality, are data of human experience: physical, historical, moral, aesthetic and religious experience. Facts per se do not yield knowledge in the scientific sense. Only the constitution of these facts into a meaningful structural whole by the application of method does. This intelligible whole illuminates the truth of the theory in the sense that it is universally understood. All scientific knowledge - including philosophical perspectives - is 
man-made and the human mind is the critical denominator of all human truth. Thus, method emerges as the truth-function of knowledge. It is achieved through a constitutive methodological act. Since the methodological constitution and reconstitution of knowledge from experience takes place under changing historical conditions, it follows that the theories yielded by this act are changing truth-perspectives, reflecting changed circumstances of life. Hence, the question about truth has to be asked again and again. Theories entering into a critical relationship with one another, philosophical argument will continue as long as there are men.

\section{PHLLOSOPHICAL THBORIES IN HISTORICAL CONTEXT}

It is really its history which affords us full understanding of philosophy. It is by analysing philosophical theories in historical context that man's permanent striving for truth becomes meaningful. As human self-projections into the world they reflect such striving, which appears to be generated by man's need of freedom from conflict. Hence, man's aspiration for knowledge of absolute truth. If such knowledge were attainable, man would be able to derive authentic existence from it. From the knowledge of the Absolute he could derive the structure of the world, his position in the world and his relationship with his fellow-man. If those conformed to each other, the principle of identity would be fulfilled. Man's feelings of uncertainty, insecurity, unease and frustration the result of the experience of conflict - would yield to feelings of certainty, security, hope and peace of mind: happiness. Great philosophers, such as Plato, realized that their attempts to comprehend the Absolute are futile. Plato, for example, became aware that rational insight into the cosmos and the human soul might afford him apprehension but not comprehension of absolute truth. He, therefore, postulated it as a hypothesis, a noble lie, necessary for meaningful existence ( $\mathrm{Cf}$ the transcendental subjectivity of Plato's theos concept in the Republic 211-212).

Man's striving for freedom from conflict, for absolute truth and for authentic existence can be clearly discerned in historical philosophical projects, no matter by what method they are developed: the dialectical and deductive (Plato), the inductive (Aristotle, Locke), the transcendental (Kant), the 
dialectical (Hegel, Marx), the phenomenological (Husserl), the analytical (Wittgenstein). This also holds true for the contemporary "anti-methaphysical" alternatives: phenomenology, analytical philosophy, existentialis $m$ and Marxism. Viewed in general, it may be said that their basic method is reductionist, instead of constitutive, the latter being the case with the philosophy of the past. Instead of deriving the structure of the world, man's position of the world and his relationshop with his fellow-man from a self-constituted premise or sufficient reason, such as ideas on the one hand and sense-impressions on the other by the deductive and inductive methods respectively, they reduce philosophy to functions, acts and operations. Examples are the intentional (functional) act of consciousness in phenomenology, the analytical activity of tracing functional language relations in analytical philosophy, the existential act of self-creation in nothingness in existentialis $m$, the operational act of selfemancipation by changing the world and human consciousness through labour in Marxis $m$. Therefore, the reductionist approach of contemporary philosophical alternatives may be described as functionalism (phenomenology and analytical philosophy), actionalism (existentialism) and operationalism (Marxism) respectively.

On closer analysis, however, it would emerge that contemporary "anti-metaphysical" alternatives turn out to be as transcendental and metaphysical as philosophical alternatives of the past. The variety and contradictions of theories within and between contemporary philosophical alternatives alone show that we are faced with various world theories, seeking to cope with contemporary historical conditions: the prevailing conflicts of the present and the needs arising from them, which are experienced by contemporaries in various ways. These theories are really transcendental and metaphysical, in that Husserl's intential act (phenomenology), Wittgenstein's pictorial relationship between natural events and propositions in the Tractatus Logico-Philosophicus (1922) and his concept of language games in Philosophical Investigations (1958) (analytical philosophy), Sartre's act of self-creation in nothingness (existentialism) and the Marxists' act of self-emancipation by changing the world through labour are world formulae. They correspond to the world formulae of classical philosophy: Plato's eros in the rational striving for goodness, Aristotle's and Thomas Aquinas' syllogistic world structure, Descartes' cogito, ergo sum principle, Kant's transcendental consciousness, Hegel's Absolute Spirit, Schopenhauer's will-to-live, Nietzsche's will-to-power. 
From this, the reflective, trasacendental and metaphysical character of contemporary world theories becomes manifest. In terms of their respective world formulae, they constitute the world in the same way as do the world formulae of classical philosophy.

The transcendental character of contemporary "antimetaphysical" alternatives points to the constitutive nature of their various world theories in which the old Platonic ideas emerge. For as is shown by the therapeutic concern of analytical philosophy to set man free from the neurosis of risking philosophical, or metaphysical, questions ( $\mathrm{J}$ Wisdom, 1953); the existentialist concern to set man free from selfalienation in bad faith ( $J-P$ Sartre, 1969); the Marxian and Marxist concern to set man free from repressive industrial society ( $K$ Marx, 1956-1974, supplementary volume, part 1) and the equally repressive monolistic technological society of the present ( $J$ Habermas, 1968), contemporary philosophical theories reflect man's need for freedom from conflict and his striving for truth, justice, harmony and goodness. As in classical philosophy, in contemporary "anti-metaphysics", too, it is the old Platonic values which - despite new reductionist methods and explicit emphasis in existentialist and Marxist thinking - forge the unity between theory and practice under the principle of identity: man's reconciliation with the world, himself and his fellow-man (society). It is evident that contemporary "anti-metaphysical" theories are problematic and controversial and that they enter into a critical relationship with one another. The latter can be either destructive or constructive, depending on whether these theories are regarded as conclusive and closed, which would lead to dogmatic monologue, or as modifiable and open, which leads to positive, if critical, dialogue. Accordingly, contemporary philosophical theories can play a constructive rôle when they are viewed, and view themselves, as critical and self-critical members of the continuing philosophical argument as it is mirrored in the history of philosophy.

The history of philosophy reflects the continuing dialogue between man and his fellow-man as a critical argument concerning the great themes of knowledge, justice, freedom and authentic existence: the argument concerning truth and the good life. Philosophical argument is practice-directed, in that philosophical theories seek to overcome the sociopolitical conflicts experienced at a particular time. The dynamics of philosophical argument is generated by the 
experience of these conflicts and the need arising from them. While thus philosophical theories have the same aim of achieving man's freedom from these conflicts and establishing his authentic existence under changing historical conditions, the method of doing so changes and the contents of these theories vary as a result of life's changing circumstances. While Plato and Marx, for example, ask the same basic questions about knowledge, reality, justice, freedom and authentic existence - about the good life - they do so in the face of different historical conditions. They cannot therefore possibly have the same truth-perspective, for their experience of reality differs.

It has already been pointed out that the historical philosophical theories enter into a critical relationship with one another, which shows the historical process of philosophical thinking as a continuing critical argument. This critical relationship through which philosophical theories are referred to one another, shows man as the rational denominator of this continuing process, which is of logical, epistemological, metaphysical and ethical significance.

\section{LOGICAL ASPECT}

This aspect of the critical relationship between philosophical theories consists in the fact that absolute truth or the Truth cannot be comprehended by man. From the logical point of view it shows the truth of not-knowing the Truth. The Logos transcends man's grasp. He can only conceive multiple logoi. Each philosophical theory contains its own logos. The logos is grasped by man in a broken form. It may be said to dawn in philosophical argument in so far as such argument - in order to be meaningful - presupposes universal features. That this is so hails from the fact that philosophical theories are universally understood, regardless whether or not they are universally assented to. If they were not understood by those who disagree, such disagreement as well as philosophical argument would be impossible. There are thus in philosophical argument universal features which point to the Logos, the existence of which is presupposed as is proved by the continuing search for it. Man's realization of the unknowability of the Truth, the truth of not knowing the Truth, constitutes a docta ignorantia, which seems to say: ignoramus ignoramibus. But it is precisely this critical insight 
into the limits of our reasoning which keeps the philosophical argument going. It is for this reason that a philosophia perennis exists.

\section{EPISTBMOLOGICAL ASPECT}

This aspect of the critical relationship between philosophical theories indicates the empirical limit of human knowledge. The critical relationship, which is experienced as conflict by man and his fellow-man, points to the polemical and controversial character of philosophical theories, to the fact that they call each other in question. In view of this state of affairs, the knowledge of absolute truth is impossible. The world can be known only in the form of changing truthperspectives, which are related to preceding truth-perspectives through critical insight and argument. They are further related to the historical conditions of the time from which they are conceived. The empirical limit of our knowledge means that the critical relationship reflects man's experience of conflict and his need for overcoming it, which forms the epistemological incentive: striving for knowledge. The realization of the empirical limit of human knowledge, the insight that the world can be known only in the mode of changing truth-perspectives means that the concept of knowledge changes with the times. Therefore epistemological argument continues, preventing a particular human truthperspective from being regarded as absolute and its hypotheses as the Truth. As has already been pointed out, the absolutization of any truth-perspective would terminate critical philosophical argument and turn philosophy into a closed system: an ideology.

\section{METAPH YSICAL ASPECT}

This aspect of the critical relationship between philosophical theory points to the other as man's real transeendent in the act of constituting and reconstituting the world on the grounds of man's contingent experience of reality. It is in the wake of critical dialogue between man and his fellowman that ever new world theories are constituted from their common experience of natural conflict and their common need for freedom from the conflict. While philosophical world 
theories are transcendental by deriving the world's structure, man's nature and the social structure from some selfconceived real ground or sufficient reason, they can never be transcendent. The controversial nature of these world-theories means that they can never grasp reality conceptually because they are the outcome of reality: man's contingent experience of it. They are confined to the dynamics of critical argument, which points to man's natural experience of conflict with his fellow-man and in which man's contingent experience of reality is reflected. It follows that reality cannot be constituted by one specific world theory, but that the latter is called in question by man's fellow-man. Reality is the changing world experience common to all men. From this basic universal experience world theories are constituted under changing conditions of life. Those world theories are linked through critical argument. From the metaphysical point of view, therefore, the world is not a universum but a multi-versum of changing human truth-perspectives of the world. In this sense the world is in a constant state of becoming.

\section{ETHICAL ASPECT}

From the ethical point of view the critical relationship between philosophical theories indicates the moral ought, which issues from the experience of natural conflict between man and the other as a result of their contingent experience of reality. The experience of natural conflict with his fellowman induces man to respond to the latter's claim in a responsible manner by taking into account the latter's truthperspective, which calls in question his own. The experience of natural conflict makes man realize that he is referred to his fellow-man in the struggle for freedom and authentic existence, that this struggle is a common one in which the other is his indispensable partner. The other is both limiting and expanding him, negating and confirming him. He cries halt to his limitless ambition, to his absolute will-to-power, but in doing so confirms him as an individual in his own right, preventing him from losing his individuality by allowing himself to be swallowed up by some totalitarian ideology or another. Man's thinking and acting takes place not in isolation, or even insulation, but with constant reference to his fellow-man, who is his yardstick and beacon in the struggle of life. The critical relationship between man and the other must be seen as a bridge rather than a wall, a 
link which makes possible a real encounter and real com munication.

The moral ought indicated by the critical relationship between philosophical theories is a challenge to man and his fellow-man to restrict themselves to their common field of action: their contingent experience of reality. This experience manifests itself in their argument about freedom and authentic existence. This means that, in their thinking and acting, they should keep themselves open for the other's truth-perspective, that they should leave behind their egocentrism and turn outward to the other man's truth. In other words, in all their thinking and acting they should observe the virtues prescribed by the moral ought: mutual self-restraint, modesty, tolerance, open-mindedness, respect and goodwill. If this happened, the argument about truth, freedom and authentic existence could be carried on in a constructive spirit. Man and his fellow-man would have an open mind for their respective needs and aspirations, as they are reflected in their respective truth-perspectives. An attempt would be made to reconcile the two in the common interest, for the purpose of coping with the existing conflicts of the situation.

All in all, the critical relationship between philosophical theories refers man and his fellow-man to the field of contingent experience as the realm of freedom. On the grounds of this experience they are free to project their respective truth-perspectives, which reflect their specific needs and aspirations. Since in all their thinking and acting man and his fellow-man are referred to one another and dependent on one another, an attempt to realize their needs and aspirations in isolation must be considered immoral. Such an attempt would be the unrestrained assertion of the willto-power, which would lead to the domination of one party over the other with all destructive consequences. The realization of those needs and aspirations, therefore, ought to occur with reference to the other, taking into consideration the latter's needs and aspirations. Since such action would involve a certain sacrifice by either party in the common interest, it is understood why altruism is judged moral while selfishness and egocentrism are judged immoral. 


\section{CONCLUSION}

In the light of the critical relationship obtaining between historical philosophical theories, which shows philosophy as continuing critical argument, man ought to reverse his way of thinking by taking his starting-point not from a particular theory or approach, but from his contingent experience of reality. On the grounds of this experience, he is already free. He must take care that he does not forfeit his natural freedom by an act of total self-transcendence by the absolutization of some theory or another. Since all man-made theories issue forth from contingent experience and enter into a critical relationship with each other, which results in continuing argument about the good life, it becomes evident that both knowledge and morality, theory and practice have their common root in this experience.

From all this, it has been demonstrated that the historical dynamics of philosophical argument is man's mirror in the sense that it shows his limitations in his striving for knowledge. In doing so, it prevents him from overreaching himself, thus conjuring up the danger of self-destruction. In warning him of the peril of self-extinction that lies in the act of total self-transcendence, it has a positive, constructive and wholesome effect. It makes him realize that the historical process of philosophical thinking forms a coherent whole, of which contemporary philosophical alternatives are the outcome. The experience of the head-on collision between these alternatives might cause him to think about the present situation, which is characterized by the antagonis $m$ between Eastern ideology and Western monopolistic technocracy. In the face of this destructive confrontation, which might bring about man's self-extinction, the realization grows that violence is not the way out of the present dilemma. The very unease, fear and frustration which are acutely experienced by the present generation, might, after all, prove a turning-point. It might induce man to reconsider his present one-dimensional way of thinking: a purely pragmatic way of thinking in technological, economic and administrative categories, which betrays an insatiable will-to-power. The negative experiences engendered by the monopolistic technological society on the one hand and ideologistic society of the hierarchy of party-functionaries on the other, might induce man to search for a way out of the present impasse and look for a new beginning, a new way of thinking. 
Such a new way of thinking must be a break-through to reality as it is experienced by all men: the contingent experience of reality. The awareness of this experience as the basis of all thinking and morality, theory and practice, would allow man to emancipate himself from the functionalistic forces which, at present, dominate his mind, level his consciousness and turn him into a faceless robot. No longer is he seen as a person but as a social function in interaction with other social functions. It is those functional interactions that replace human relations. It is not man's human qualities that are valued, but skilled man-power, which is needed by technological society. It is when man's thinking and acting are seen as a continuing dynamics of critical argument generated by the contingent experience of life that he might become aware of the versatility of human life which is reflected in the multiple diversity of his theories. The one-dimensionality might yield to man's authentic multidimensionality, which latter cannot really be fathomed. In becoming aware of his natural limits staked out by die dynamies of philosophical argument, he might rediscover himself as a fully-fledged individual, who in his thinking and acting is responsible to his fellow-man. This might help him to rediscover his equilibrium as a person and so to live in peace with the world, himself and his fellow-man. Learn to know thyself through philosophy and the world might become a better place. Philosophy is man's mirror. 